\title{
Features of emotional burnout among teachers of higher education institutions
}

\author{
O.I. Politika ${ }^{1 *}$, E.P. Salnikova ${ }^{2}$, and E.M. Yevtushenko ${ }^{3}$ \\ ${ }^{1}$ Bashkir State University, Ufa, Russia \\ ${ }^{2}$ Bashkir State University, Ufa, Russia \\ ${ }^{3}$ Bashkir State Medical University, Ufa, Russia
}

\begin{abstract}
The article discusses and describes in detail the specifics of equipping the system of higher professional education with tools of modern pedagogical technologies - game technologies that have a significant impact on the quality of professional training of future specialists and their motivation to obtain general and special competencies. The most relevant game technologies are considered separately, and their effectiveness (or inefficiency) is confirmed by means of a survey of leading teachers of the Crimea who actively use game technologies in their teaching practice. The author compares the opinions of various scientists (both practitioners and theoretical researchers) who address the study of the system of modern pedagogical technologies in general and game technologies in particular, on the basis of which a comprehensive conclusion is made, which is reflected in the final part of the article. A special place in the structure of the study is occupied by the selected key method - a questionnaire based on data provided by more than 100 teachers of higher and secondary professional education.
\end{abstract}

\section{A problem statement}

Teacher burnout is a particular type of stress at work, a state of physical, emotional, or mental exhaustion combined with doubts about the competence and value of the job.

The problem of professional burnout is one of the most relevant, since it has a negative impact on many indicators of the organization's activities. The negative consequences of professional burnout should not be underestimated, and the measures implemented in this area in some cases are of a formal nature.

Today, we can observe contradictory processes in the field of higher education. On the one hand, many university teachers are afraid of losing their jobs and, therefore, work harder to prove their worth. On the other hand, an increasing number of teachers are unable to cope with difficulties and are forced to resign. As a result, the additional burden falls on the remaining employees, who, in turn, must work beyond the norm. However, in most cases, they do not receive gratitude and professional recognition from their supervisors, as a

\footnotetext{
*Corresponding author: prof-ped.gpa@mail.ru
} 
result of which their frustration with their chosen profession increases against the background of increasing stress.

Often, the teacher does not understand that the burnout process has begun. This is largely due to the peculiarities of his labor process, which is characterized by an unnormalized amount of working time spent. In addition to academic work, the teacher should be engaged in research, scientific and organizational, career guidance and educational activities. Distance learning, which is widely practiced at the present time, also has an impact on the activities of teachers. This requires additional physical effort and emotional stress.

In order to identify the signs of the beginning of professional burnout, the teacher should ask himself a number of questions: whether I have become cynical or critical at work; whether I have irritability in relations with colleagues; whether I have enough energy to complete work tasks; whether my behavior habits or appetite have changed; whether I am worried about unexplained headaches, back pain or other physical complaints. If he answers "yes" to any of these questions, we can talk about the initial stage of professional burnout.

Assumptions about activity, about the possibility of conscious self-regulation based on reflexive ideas about the purpose, methods and means of self-regulation, about selfdetermination as the ability and need to independently choose the direction of their own development came to the fore.

It can be assumed that the burnout syndrome, characterized by the emotional dryness of the teacher, the expansion of the sphere of saving emotions, personal detachment, ignoring the individual characteristics of students, has a fairly strong influence on the nature of professional communication of the teacher. This professional deformation hinders the full management of the educational process, the provision of necessary psychological assistance, and the formation of a professional team. Real pedagogical practice shows that today the fact of loss of interest in the student as a person, rejection of him as he is, simplification of the emotional side of professional communication is quite clearly traced. Many teachers note the presence of mental states that destabilize professional activities (anxiety, despondency, depression, apathy, frustration, chronic fatigue).

\subsection{The objective of the work}

In this regard, there is an increasing interest in studying the relationship between the style of activity and self-regulation of higher school teachers. The main questions devoted to the style of activity of teachers are consecrated in the works of E.A. Klimov, V.S. Merlin, E.P. Ilyin, V.A. Tolochek, M.R. Shchukin and other researchers. In the works of these authors, a fairly wide range of problems related to the style of pedagogical activity is highlighted: the psychological structure of the activity, the style of the teacher's activity, the process of forming the teacher's personality, etc. At the same time, studies that highlight the relationship between the teacher's self-regulation style and emotional states are not fully presented. The teacher has to resist the influence of emotional factors of the modern professional environment.

All this led to the choice of the research topic "The relationship of the organization of activity, the style of self-regulation and professorial burnout of teachers of higher education institutions".

The problem of professional health was studied by V.A. Ponomarenko, A.G. Maklakov, G.S. Nikiforov, S.A. Druzhilov, N.E. Vodopyanova, R.A. Berezovskaya, E.S. Starchenkova, and others. Research by psychologists shows that there is a relationship between work and personal life, however, the problem of rest as the restoration of 
professional health is still poorly understood. Therefore, this topic requires a more detailed and in-depth study.

\section{Results of the research}

The study was conducted in the period from September 2018 to September 2020 on the basis of the Bashkir State Pedagogical University named after M. Akmulla. The total sample of the study was 50 people: 34 women and 16 men aged 28 to 67 years.

The psychodiagnostic tools include the following psychodiagnostic techniques:

1. Burnout questionnaire by V.V. Boyko.

The results obtained when testing teachers using the method of diagnosing emotional burnout of the personality of V.V. Boyko are summarized in Table 1, Appendix 2.

All subjects are divided by the number of points scored, both in individual phases, and by the total number of points scored.

The entire sample can be divided into three groups, according to such criteria as the formation of phases:

group 1-the syndrome is fully formed in at least one of the phases (i.e. the total number of points in one of the phases is greater than or equal to 61);

group 2-the syndrome is in the stage of formation in at least one of the phases (i.e. the total number of points in one of the phases is in the range from 37 to 60 points);

Group 3-the syndrome has not formed (i.e. the total number of points in any of the phases does not exceed 36 points) (Figure 1).

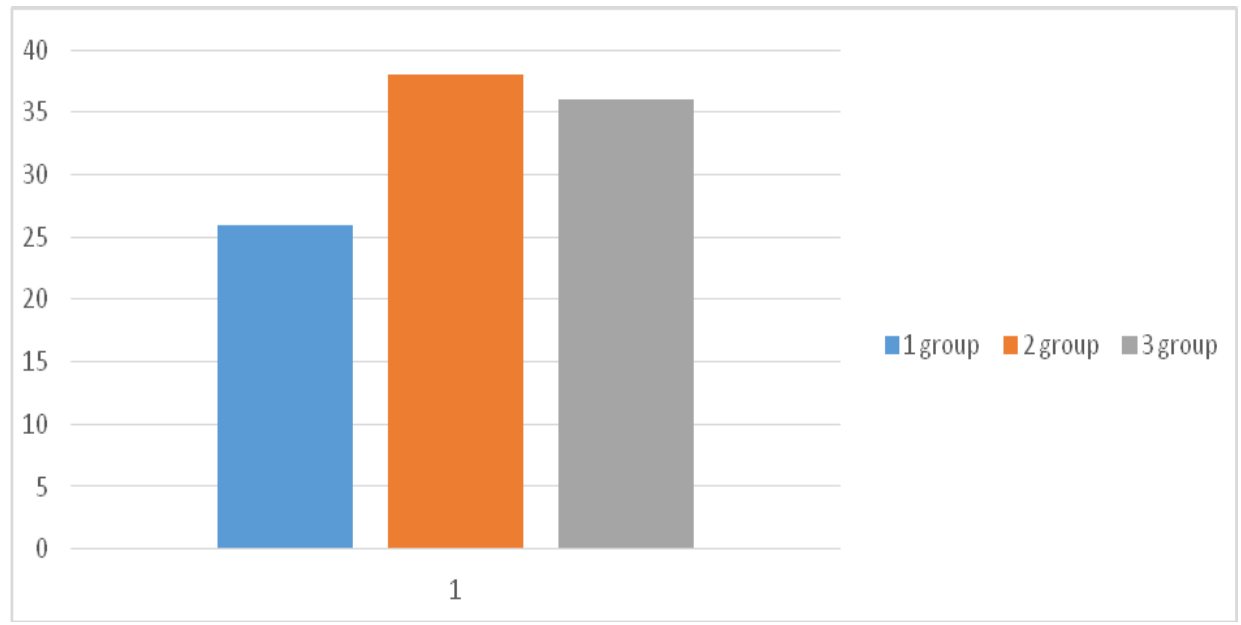

Fig. 1. Distribution of teachers by stages of emotional burnout, $\%$.

Figure 1 shows that the first group included 13 teachers, which is $26 \%$; the second group -19 people, which is $38 \%$; the third group- 18 people, which is $36 \%$.

Thus, we can conclude that the most numerous group of teachers was a group of teachers with burnout syndrome, formed at least in one of the phases. Individuals who fall into this group are characterized by a drop in overall energy tone and a weakening of the nervous system. "Burnout" becomes an integral attribute of these teachers. And the smallest group is the group with an unformed syndrome. These teachers "started" the mechanism in the formation of emotional burnout. Teachers experience personal anxiety, disappointment in themselves, in the profession or place of work.

Figure 2 shows the symptoms of the "stress" phase. 


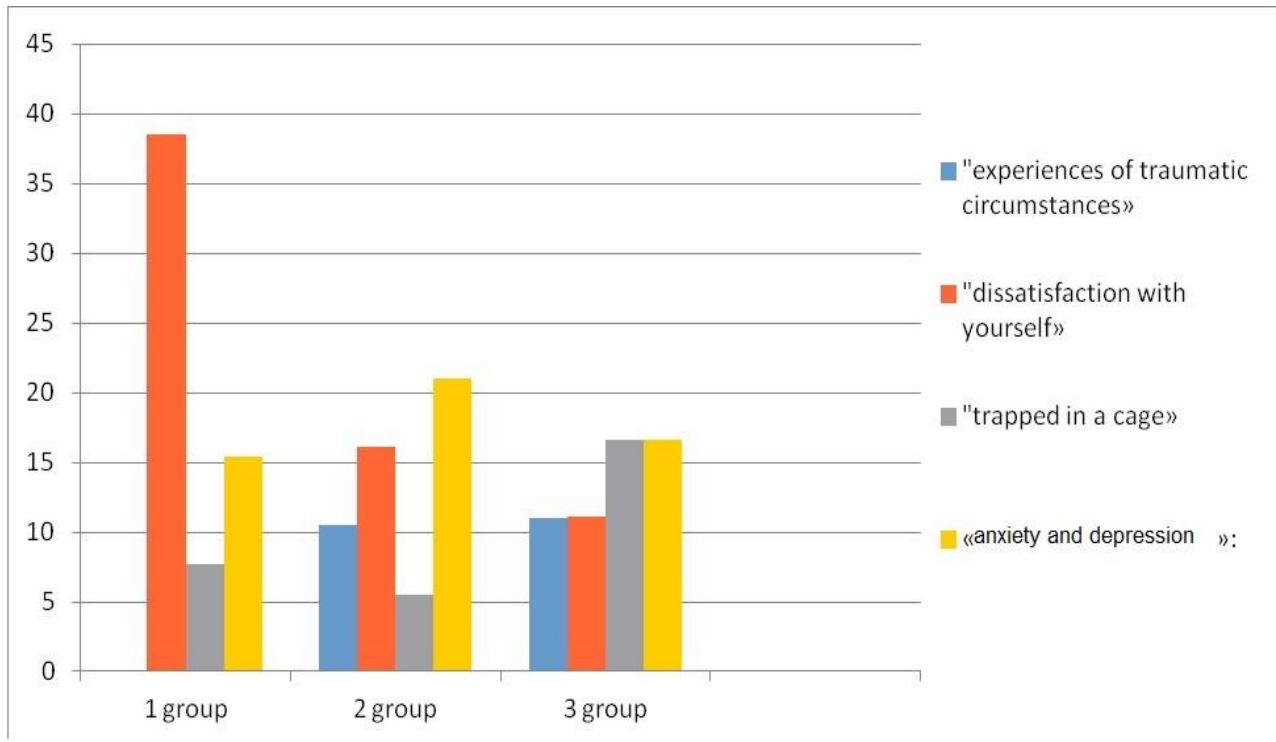

Fig. 2. Symptoms of the "stress" phase in teachers, $\%$.

Analyzing the indicators of the figure, we can say that in the "tension" phase, in the first and second groups, the "feeling of dissatisfaction with oneself" symptom dominates. The feeling of "dissatisfaction with themselves" was formed in a relatively large number of teachers, which indicates that teachers are dissatisfied with themselves in the profession and with specific circumstances in the workplace. But in $39.3 \%$ of teachers from all three groups, this symptom begins to develop, and we can say that the mechanism of "emotional transfer" begins to work, that is, all the power of emotions is directed not to the outside, but to oneself. This manifests itself in an intense interiorization of duties, increased conscientiousness and a sense of responsibility, which undoubtedly increases tension, and in the subsequent stages of "burnout" can provoke psychological protection.

The symptoms of "experiencing psychotraumatic circumstances" also occupy a large place, which means that teachers of these groups are currently experiencing the impact of psychotraumatic factors, increasing tension, which results in despair and indignation. The unsolvability of the situation leads to the development of the phenomena of "burnout".

The symptom of "caged" in the two groups was formed in $11.1 \%$ of teachers and another $18.8 \%$ is in the process of formation. This means that these people feel or begin to feel a state of intellectual and emotional congestion, deadlock. This can lead to organizational shortcomings, daily routine, etc. In the third group, this symptom is also observed.

The last symptom in this phase, the symptom of "anxiety and depression" developed in a significant number of teachers $(22.5 \%)$ from the first group, this indicates that these people experience tension in the form of experiencing situational and personal anxiety, frustration in the profession. The developed symptom of nervous anxiety means the beginning of resistance to stressful situations and the beginning of the formation of emotional protection.

In the "resistance" phase, the dominant symptom is the "expansion of the sphere of saving emotions" (Figure 3). 


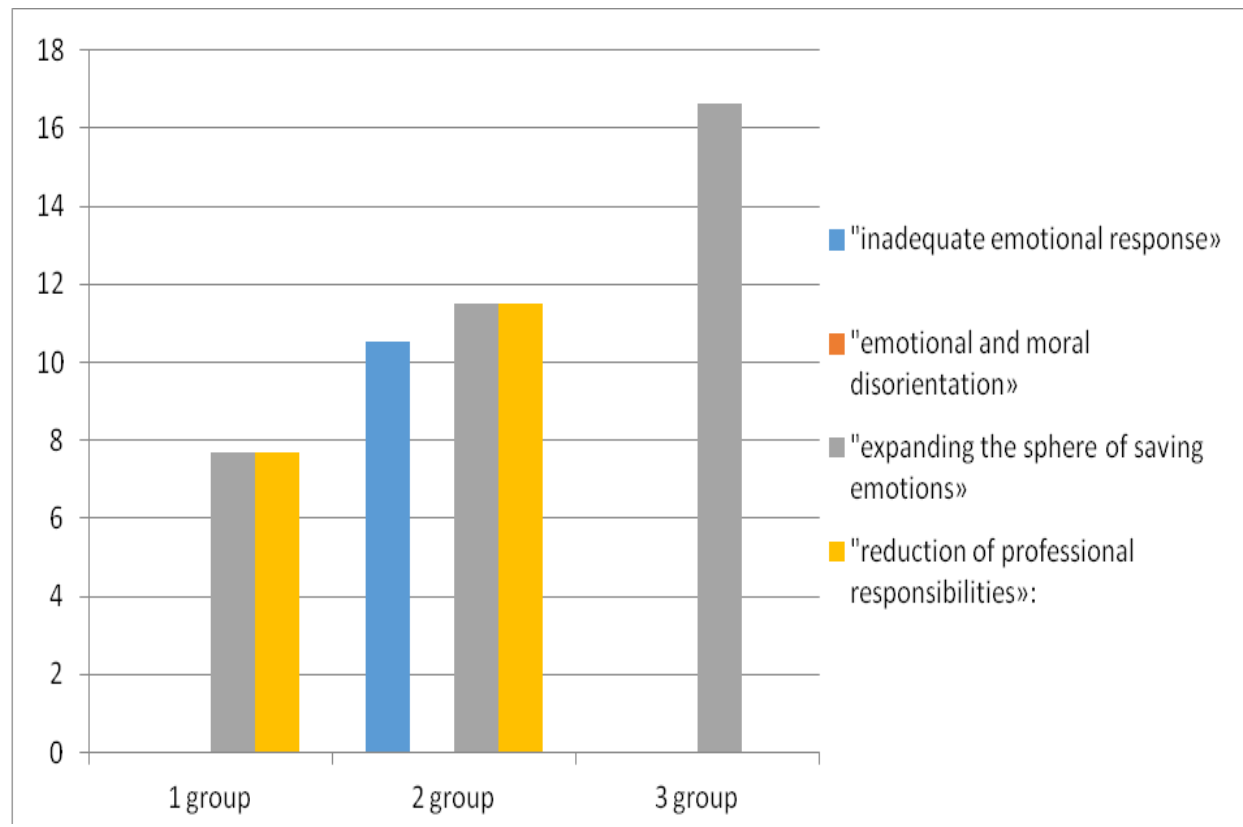

Fig. 3. Symptoms of the "resistance" phase in teachers, \%.

This symptom developed in $10.8 \%$ of PPS, in $24.2 \%$ - it develops. Of these, $7.7 \%$ are in the first group, $5.3 \%$ in the second and already $11.1 \%$ in the third group. This suggests that this form of protection is carried out outside the professional field - in communication with family and friends. At work, these people keep to the standards, and at home they lock themselves in or, worse, they are ready to send everyone away.

The next most pronounced symptom is the "reduction of professional responsibilities". This symptom developed in $7.7 \%$ of teachers from the first and second groups $(7.7 \%$ and $5.3 \%$ ) and develops in 5.3\% of teachers, of which: $7.7 \%$ belongs to the first group, $5.3 \%$ to the second group, and in the third group was not observed. This means that these teachers are trying to ease or reduce the responsibilities that require emotional costs. One example of this simplification is the lack of elementary influence to students and colleagues.

This is followed by a symptom of "inadequate emotional response". This symptom developed in $5.3 \%$ of teachers. The first group of respondents is not observed, the second group accounts for $5.3 \%$ each. In the third group, this symptom did not develop. The formation of this symptom suggests that the teacher ceases to grasp the difference between two fundamentally different phenomena: the economical manifestation of emotions and inadequate selective emotional response. Inadequate "economy" of emotions limits the emotional return due to selective response during work contacts. At the same time, it seems to the person that he is acting in an acceptable way. The subject of communication records something else - emotional callousness, indifference and disrespect for the individual.

In this phase, in our observations, the symptom of "emotional and moral orientation" is not observed. For such teachers, moods and subjective preferences affect the performance of professional duties. The teacher tries to solve the problems of the wards of his own choice, determines the worthy and unworthy, "good" and "bad".

In general, the phase of "resistance" was formed in $16.6 \%$ of teachers, is in the stage of formation in $21.4 \%$, and was not formed in $15.4 \%$.

In the "exhaustion" phase, the dominant symptom is "emotional deficit", which was formed in $23.1 \%$ of teachers (Figure 4 ). 


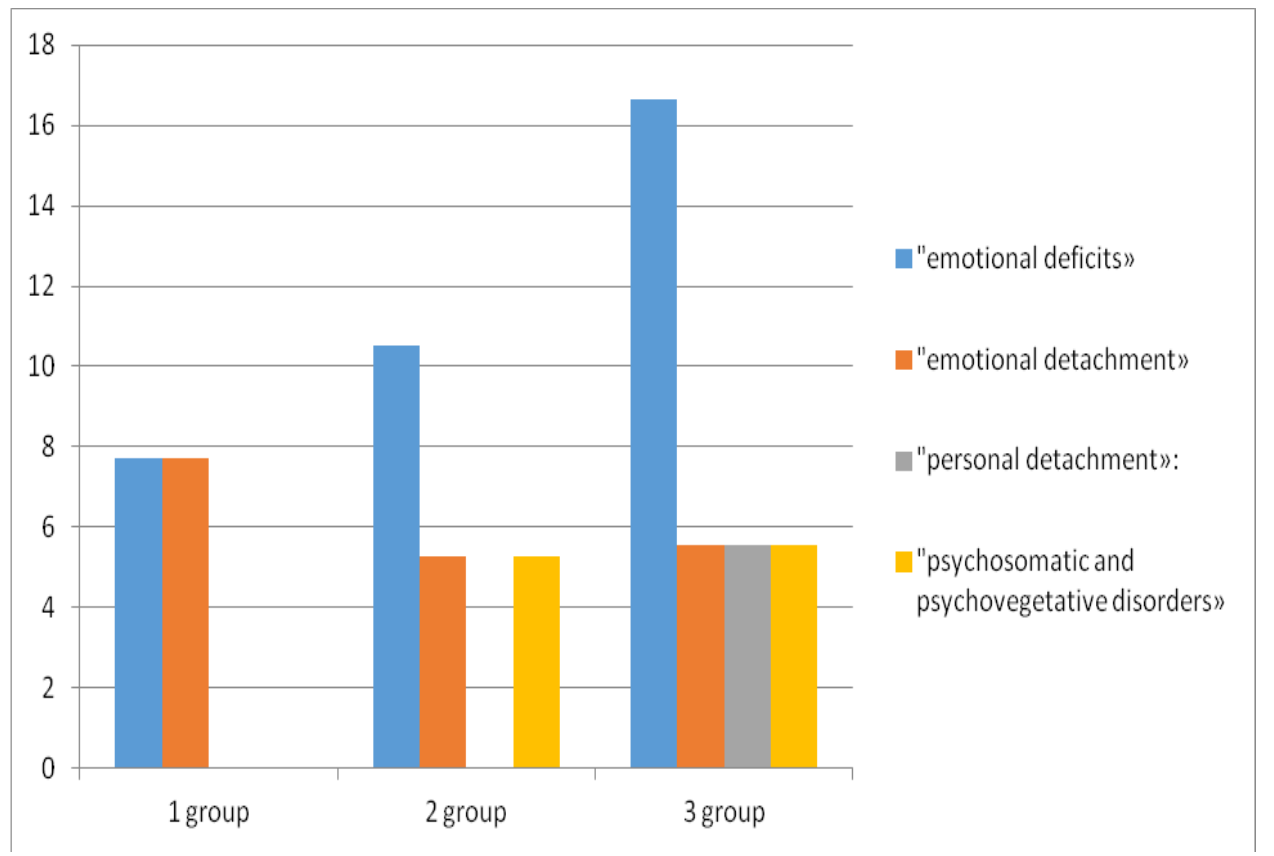

Fig. 4. Symptoms of the "exhaustion" phase in teachers, $\%$.

Of these, $15.4 \%$ belong to the first group and $10.3 \%$ - to the second. In the third group, the symptom also occupies a significant place $-16.7 \%$. This symptom is formed by $17.5 \%$ of teachers, of which: $7.7 \%$ belongs to the first group, to the second group $-5.3 \%$ and $5.6 \%$ to the third. It manifests itself in a sense of its inability to help the subjects of its activities in an emotional way, unable to enter into their position. At the same time, the person experiences the appearance of these sensations. If positive emotions are less frequent and negative emotions are more frequent, then the symptom is getting worse. Rudeness, irritability, resentment - all these are manifestations of the symptom of "emotional deficit".

Next in severity is the symptom of "psychosomatic and psychovegetative disorders". The symptom did not fully develop in the teachers. It is formed in $10.8 \%$ of teachers who belong to the first and second groups $(5.3 \%$ and $5.6 \%)$. This symptom means that the syndrome manifests itself in somatic terms, manifests itself physiologically: insomnia, pressure surges, tachycardia, in most cases, several symptoms together.

The least pronounced symptom was "emotional detachment". It was formed in $7.7 \%$ of teachers, all of them belong to the first group. In the other groups, this symptom is not observed. Teachers affected by this symptom almost completely exclude emotions from their professional activities. They almost do not care, do not cause an emotional response neither positive circumstances, nor negative ones.

The symptom of "personal detachment" is formed in the third group of $7.7 \%$ of teachers. This symptom manifests itself in the process of communication in the form of a partial loss of interest in the subject of professional activity ("To everything that happens at work, I have lost interest, a lively feeling").

In general, the phase of "exhaustion" was formed in $27.5 \%$ of teachers, in the stage of formation in $22.5 \%$ and not formed in $50 \%$ of teachers.

Thus, it can be seen that the largest number of teachers is in the first phase of emotional burnout, in the phase of "tension" - resistance. The "depletion" phase also occupies a significant place among the teaching staff of the BSPU named after M. Akmulla. As the results show, it is necessary to beware of the development of symptoms of professional 
burnout, it is necessary to organize work to identify the manifestations of burnout and develop a style of self-regulation of higher school teachers. When carrying out certain correctional work, a greater number of teachers can cope with the negative manifestations of the burnout syndrome.

The understanding that various organizational working conditions (the order and content of activities, work requirements, work resources) and individual-style features of selfregulation of university teachers ' activities can act as factors for the development of professional burnout syndrome, determined the further study of the style of self-regulation of teachers. For this purpose, the questionnaire of V.I. Morosanova was used.

The analysis of the self-regulation style assessment revealed the following results:

A high level of "Planning" was shown in $14(28 \%)$ of respondents. This indicates that teachers consciously plan their activities, correctly prioritize the implementation of their plans. The average level on the "planning" scale was shown in 27 (54\%) of respondents. A low level on the "planning" scale was shown in $9(18 \%)$ of respondents. Such teachers rarely achieve their goals, their goals are unrealistic and often change.

A high level on the scale of "Modeling" was found in $32(64 \%)$ of respondents. They are able to identify significant conditions for achieving goals, both in the current situation and in the long-term future. The average level on the "modeling" scale was found in 11 $(22 \%)$ respondents. A low level on the "modeling" scale was found in 7 (14\%) respondents. Such teachers are characterized by an inadequate assessment of the ratio of internal resources and external circumstances, which is manifested in fantasy, which can be accompanied by sharp changes in attitude to the development of the situation, as well as the consequences of their actions.

A high level on the "programming" scale was shown in $13(26 \%)$ of respondents. These teachers have a high need to think in detail about the ways of their actions to achieve their goals. The average level on the "programming" scale was shown in $19(38 \%)$ of respondents. A low level on the "programming" scale was shown in 18 (36\%) of respondents. Such teachers are characterized by inability and unwillingness to think through the sequence of their actions, they prefer to act impulsively, subsequently encountering the inadequacy of the results obtained for the goals of the activity.

A high level on the scale of "evaluation of results" was found in 23 (46\%) of respondents. Teachers have formed an adequate self-assessment, the stability of subjective criteria for evaluating results, and are aware of both the fact of the discrepancy between the results obtained and the purpose of the activity, and the reasons that led to it. The average level on the "evaluation of results" scale was found in $24(48 \%)$ respondents. A low level on the "evaluation of results" scale was found in $3(6 \%)$ of respondents. Such teachers tend not to notice mistakes in their activities and to be uncritical of their actions. Subjective criteria for success are not sufficiently stable, which can affect the quality of results with an increase in the volume of work.

A high level on the "flexibility" scale was shown in $12(24 \%)$ of respondents. Such teachers demonstrate the plasticity of all regulatory processes. They are able to quickly assess changes in significant conditions and, if necessary, adjust their plans. If there is a mismatch of the results obtained with the accepted goal, the fact of mismatch is evaluated in a timely manner and appropriate changes are made. The average level on the "flexibility" scale was shown in $28(56 \%)$ respondents. A low level on the "flexibility" scale was shown in $10(20 \%)$ of respondents. Such teachers have difficulty getting used to the rapid change of the situation, are not able to adequately respond to the situation, assess the discrepancy between the results obtained and the purpose of the activity, and make changes in a short time.

A high level on the scale of "independence" was found in $12(24 \%)$ of respondents. Such teachers are characterized by autonomy in the organization of activities in achieving 
goals, monitoring its progress, analyzing and evaluating both intermediate and final results. The average level on the scale of "independence" was found in $34(68 \%)$ of respondents. A low level on the scale of "independence" was found in $4(8 \%)$ of respondents. Such teachers are dependent on the opinions and assessments of others. In their activities, they act with the help of other people, in the absence of this help, they have regulatory failures.

A high level on the scale of "general level of self-regulation" was shown in $13(26 \%)$ of respondents. The peculiarity of such teachers is that they are independent, easily and quickly adapt to the change of circumstances, consciously set goals and achieve them. With a high motivation for achievement, they are able to form a style of self-regulation that allows them to compensate for the influence of personal characteristics that sometimes hinder the achievement of goals. The average level on the scale of "general level of selfregulation" was shown in 27 (54\%) of respondents. A low level on the scale of "general level of self-regulation" was shown in $10(20 \%)$ of respondents. Such PPS do not have a conscious planning of activities, and the possibility of compensating for personal characteristics that are unfavorable for achieving goals is reduced. They depend on the situation, so the success of mastering the process of activity depends more on the compliance of the stylistic features of the regulation and the requirements of the type of activity being mastered.

\section{Conclusions}

1. Professional burnout was observed in $64 \%$ of higher school teachers.

2. Individual and personal characteristics that prevent the development of professional burnout syndrome of a higher school teacher are: high self-control, emotional stability, selfreflection, self-confidence, the need for personal and spiritual and professional growth, the ability to freely express their feelings, awareness of their unity with the world around them and a value attitude to themselves, to other people, to professional activities.

3. The higher the indicators of self-regulation, namely the processes of planning, modeling, programming, evaluation of results, and in general, the higher the level of formation of skills and skills of conscious self-regulation, the lower the level of development of professional burnout of teachers.

\section{References}

1. A.A. Baranov, Psychology of stress resistance of the teacher, 405 (2002)

2. S.P. Beznosov, Professional deformation of the personality, 272 (2004)

3. N.N. Biktina, Studying the features of self-regulation and the syndrome of emotional burnout of teachers, Modern problems of science and education, 5 (2016)

4. M.V. Borisova, Psychological determinants of the phenomenon of emotional burnout in teachers, Questions of Psychology, 2, 97-104 (2005)

5. N.E. Sherman and E.S. Starchenkov, Psychological burnout and quality of life, Psychological problems of self-identity, 6, 140-154 (2002)

6. G.N. Izmailov, Characteristics of emotional burnout of teachers with different experience, The book Self-development in pedagogy and psychology, 96-100 (2017)

7. A. Kolesnichenko, Y.O. Petrov, and A.V. Polkovnikova, The Syndrome of "burnout" of the teacher and its prevention, The book digital society in the context of personality development, 138-141 (2018) 
8. A.S. Leonov Emotional burnout of teachers of secondary and higher education: a comparative analysis, Collection of scientific works, 31-35 (2017)

9. A. Laengle, Emotional burnout from the standpoint of existential analysis, Questions of psychology, 2, 3-16 (2008)

10. T.V. Formanyuk, The Syndrome of "emotional combustion" teacher, Education, 356 (2004) 